Relations industrielles

Industrial Relations

\title{
Principes de la gestion budgétaire, M. Fuster, Entreprise Moderne d’Édition, Paris, 1965, 134 pages.
}

\section{Ronald Pleau}

Volume 20, numéro 4, 1965

URI : https://id.erudit.org/iderudit/027631ar

DOI : https://doi.org/10.7202/027631ar

Aller au sommaire du numéro

Éditeur(s)

Département des relations industrielles de l'Université Laval

ISSN

0034-379X (imprimé)

1703-8138 (numérique)

Découvrir la revue

Citer ce compte rendu

Pleau, R. (1965). Compte rendu de [Principes de la gestion budgétaire, M. Fuster, Entreprise Moderne d'Édition, Paris, 1965, 134 pages.] Relations industrielles / Industrial Relations, 20(4), 719-719. https://doi.org/10.7202/027631ar

Tous droits réservés (C) Département des relations industrielles de l'Université Laval, 1965
Ce document est protégé par la loi sur le droit d'auteur. L’utilisation des services d'Érudit (y compris la reproduction) est assujettie à sa politique d'utilisation que vous pouvez consulter en ligne.

https://apropos.erudit.org/fr/usagers/politique-dutilisation/ 
de l'emploi dans les pays en voie de développement.

Le premier article, de R.V. Gilbert, aborde la question des programmes de travail dans l'est du Pokistan. II réfute les objections contre les projets de ce genre et met l'accent sur la nécessité d'utiliser toutes les ressources humaines latentes afin de favoriser le plein emploi, prérequis au développement économique.

Le second, de $M$. Pohorille, traite de la question de la surpopulation rurale et du sous-emploi. II décrit l'expérience de la Pologne vis-à-vis la réforme ograire, l'industrialisation et la création d'emplois. II porte oftention aux mesures prises pour maintenir un niveau adéquat d'épargnes et d'invertissements dans le secteur rural pour augmenter la productivité et ossurer une production suffisante pour supporter l'expansion de la population industrielle et urbaine.

La troisième étude analyse les concepts de sous-emploi dans le contexte d'un pays sous-développé et surpeuplé. II explique la façon de mesurer le chômage dans les régions rurales selon l'expérience pakistanaise et signale les résultats obtenus.

P. Hoffman discute le cas de la Tchécoslovaquie depuis les 15 dernières années vis-a-vis l'étude de la main-d'oeuvre: productivité, mobilité, l'âge des travailleurs, l'urbanisation et lo location des industries.

Enfin, le professeur Syloo-Kabini suggère que le concept d'emploi précaire soit utilisé pour l'étude des pays sous-développés plutôt que le concept de sous-emploi et de nonemploi. II traite ensuite de la Sicile en appliquant ce concept aux secteurs agricole et non-agricole.

Ces cina études troitent donc de la situotion agricole dans les pays en voie de développement, en tentant de donner certaines règles quant au plein emploi, en tant que concept et en tant qu'objectif.

\section{Fernand Blais}

Principes de la gestion budgétaire, $M$. Fuster, Entreprise Moderne d'Edition, Poris, 1965, 134 poges.

Dans l'entreprise moderne la vogue est à la gestion budgétaire. La France ne fait pos exception et ces techniques y sont largement diffusées.

L'auteur recherche dans ce petit volume le fondement moral et intellectuel des techni- ques de gestion budgétaire sans s'attarder à nous les exposer comme telles.

En parcourant les quelques lignes de la préfoce, nous pouvons y retrouver l'optique de l'ouvrage lorsqu'on y lit: « Tout le problème de l'entreprise est que so nécessaire unité soit le fruit de l'intelligence de telle sorte que la nécessité même s'efface devant lo liberté $\$$.

Quelle est la notion américaine de gestion budgétaire? A quel besoin de l'entreprise industrielle répond-elle? Voilà le genre de questions auxquelles on répond dans une brève introduction. Et comme au point de départ cette science de la gestion budgétaire présuppose une réflexion élaborée sur lo nature, la finalité, la structure interne et les lois de développement de l'entreprise, on doit avoir une bonne connaissance de cette dernière.

Tout ceci pourra par la suite nous aider d un effort d'analyse avec comme base les concepts de l'unité et du clossement (celui des dépenses de l'entreprise surtout).

Pouvant d'autre part servir à la synthèse de cette connaissance nous étudierons la structure de l'ensemble. Pour ce point, il fout s'attarder à bien examiner les courants de l'argent et des biens, les dimensions de l'espace et du temps. On arrive ainsi à dégager le schéma général de l' « ensemble » de l'entreprise.

Enfin, l'entreprise étant un lieu où vivent plusieurs groupes de personnes, travailleurs, professionnels, directeurs, etc., il est bien important qu'y règne un système de diffusion des plus précis. C'est alors que se résoudront plusieurs problèmes psychologiques.

II n'est plus seulement question ici de la comptabilité de contrôle (de plus, il est bien important de bien voir la distinction entre le chef d'entreprise et le contrôleur de gestion) mais d'un effort de renouvellement continuel de l'entreprise par des mécanismes qui permettront aux travailleurs de participer à la vie de l'entreprise et à ses réalisations de façon complète.

Lo gestion budgétaire, en forçont l'entreprise à une économie d'efforts lui permet de pousser au-delà des limites qu'elle croyait pouvoir atteindre.

Ronald Pleau

Le perfectionnement des cadres en France et aux Etats-Unis, Pierre Demarne ovec la collaboration de Jean-Baptiste Jeener, Entreprise Moderne d'Edition, Poris, 1965, 193 poges. 